Middle School Teachers' Discipline-Specific Use of Gestures and Implications for

Disciplinary Literacy Instruction

\author{
Amy Alexandra Wilson \\ Utah State University \\ Michael D. Boatright \\ Western Carolina University \\ Melanie Landon-Hays \\ Western Oregon University
}




\begin{abstract}
Framed in theories of social semiotics, this descriptive multiple case study examined six middle school teachers' use of gestures during one school year as they each taught two different subject areas: earth science, language arts, mathematics, and/or social studies. The data, which included field notes and photographs from 354 lessons and 151 video-recordings of lesson segments, were analyzed using constant comparative methods and multimodal concordance charts. The analyses indicated discipline-specific differences in types of gestures, frequency of gestures, and centrality of gestures to the teachers' messages. Earth science depended on a variety of iconic and deictic gestures, the latter of which was also common in mathematics. Communications in language arts and social studies commonly included non-essential action gestures that mimicked the movements of characters and historical figures. This study modifies existing claims of the importance of gestures in teaching, suggesting that gestures can play relatively central or minor roles in communicating disciplinary concepts. It concludes with implications for disciplinary literacy instruction that more rigorously accounts for the role that gestures play in disciplinary learning.
\end{abstract}

Keywords: content area literacy, disciplinary literacy, gestures, social semiotics, representation 


\section{Middle School Teachers' Discipline-Specific Use of Gestures and Implications for Disciplinary Literacy Instruction}

A growing body of research (e.g., Roth, 2001; Sfard, 2009) has begun to address gestures' role in classroom instruction by describing how teachers use gestures to communicate disciplinary concepts. According to McNeill (1992), gestures almost always co-occur with speech and often indicate aspects of the speaker's message that are not available through verbal language alone (cf. Melinger \& Levelt, 2004). This presumed ubiquity and expressiveness of gestures would suggest that gestures are a central component of effective teacher communication. Indeed, according to Goldin-Meadow (2004), "the few experimental studies that have been done [addressing the effects of teacher gestures on learning] suggest that a lesson accompanied by gesture is more effective than that same lesson not accompanied by gesture" (p. 319).

This study, which examined the gestures used by six middle school teachers as they each taught two disciplines, was not based on this assumption that gestures always enhance teacher communication. Instead, this study sought to provide a more nuanced view of how gestures functioned within earth science, mathematics, language arts, and social studies, including the patterns of gesture types that were unique to each discipline and the relative communicative role that gestures played in relation to other types of representation. Specifically, this study sought to answer two research questions: (1) What discipline-specific patterns of gestures did the teachers use in their instruction?; and (2) What role did teachers' gestures play in the realization of each discipline? 


\section{A Social Semiotic Theory of Gestures}

This study is framed in social semiotic theories of multimodality (Halliday, 1978; Hodge \& Kress, 1988; Kress, 2010), which assert that members of social groups are distinguishable from members of other social groups in large part through the texts they generate, use, and exchange as they seek to accomplish mutual goals. According to these theories, a text can be defined as any instance of communication in any mode or combination of modes (Kress, 2003), and a mode is defined as a socially-fashioned resource for expressing meaning, including subcategories such as written words, gestures, images, verbal speech, and threedimensional objects. Under this theory, disciplines are realized through multimodal textsthrough line graphs written on a whiteboard and the verbal discussions surrounding them; through people's pointing gestures toward particular parts of a map; and so forth. It is through these multimodal texts that students and teachers construct and express their understandings of what it means to "do mathematics" or "do social studies."

The concept of affordances (Gibson, 1979; Jewitt, 2006), central to social semiotic theories of multimodality, offers a rationale behind why different modes are used to different extents in different disciplines - for example, why three-dimensional models and images may be used more frequently in earth science than in language arts (Wilson, 2010). A mode's affordances are determined in part by the conventions and goals of particular social groups (Jewitt, 2006; Kress, 2010), as well as by the physically observable properties of each mode, which lend themselves toward the expression of particular types of content (van Leeuwen, 2005). Although content expressed through one mode may often also be expressed through another mode, each mode's affordances enable some aspects of that content to be expressed more readily than is possible via other modes (Kress, 2003; Lemke, 1998). For example, although one could 
communicate the positions of the planets in the solar system through writing, images afford “spatial and simultaneous representation" (Kress, 2005, p. 14) as they depict gradations of color and size, affording the concurrent visualization of the planets' relative positions.

In addition to explaining why particular modes may be used to a greater or lesser extent in accordance with the disciplines' distinctive bodies of content, theories of social semiotics also explain why any single mode also assumes particular forms according to the discipline's goals, demands, and historical traditions. Halliday and Martin (1993), for example, described how the mode of written words has been shaped in scientific discourse. They analyzed changes in Newton's scientific writing, which increasingly became characterized by frequent nominalizations and interlocking classifications, and asserted that these syntactic and lexical features developed due to the need to more succinctly communicate ideas about refraction and other subjects.

We conjectured that gestures, like written words, would likewise assume particular forms according to the discipline-specific content the teachers sought to convey, and that they would be used with greater or lesser frequency in each discipline in accordance with how well they afforded the expression of discipline-specific bodies of content. The following sections situate our definition of gesture within theories of social semiotics; we then briefly synthesize existing literature on how teachers use gestures within specific academic disciplines.

\section{Gestures and the Metafunctions of Communication}

Halliday's (1978) metafunctions of communication, although initially used to theorize written and spoken language, also provide a useful heuristic for understanding gesture. According to Halliday, any act of communication simultaneously fulfills three functions. First, it fulfills the ideational function of communication through referring to phenomena in the universe 
and to people's experiences with those phenomena. In other words, this function relates a representation to its referent, whether that referent is intangible, such as an emotion, or a visible object, such as a moon. As an example, Kim, Roth, and Thom (2011) described first-grade students who placed both index fingers and thumbs together, forming a triangle, to communicate what the bottom of a triangular prism looked like. In this case, the gesture realized the ideational function of language by referring to a property of one three-dimensional solid.

Second, the interpersonal function "embodies all use of the language to express social and personal relations" (Halliday, 1973, p. 41). Through this function of language, text-makers indicate social roles for themselves in relation to the social roles they assign to their audience. For instance, McDermott, Gospodinoff, and Aron (1978) studied how one teacher used gazes and head nods in a small reading group to maintain order and control; a gaze to one student was a signal to stop talking, while a gaze and a head nod to another student signaled that it was her turn to read. As this example indicates, gestures can serve an interpersonal function through realizing the teacher as occupying a particular social position (e.g., 'in charge') as compared to students (cf. Lim, O’Halloran, \& Podlasov, 2012).

Finally, the textual function produces a comprehensible message by relating parts of the text to each other and to the context of communication. McNeill (1992) argued that beats, or the regular up-and-down movement of hands that co-occur with speech, can structure speakers' recounted narratives by emphasizing certain actions or by noting transitions to a different phase of the story. Erickson (2004) similarly argued that "shifts in gaze and posture and prominent gestures also tend to occur together with timed points of emphasis or transition in the stream of speech" (p. 36). The lifting and setting down of a pencil during an interview, for example, can 
signal a shift from one activity, such as answering questions, to another activity, such as wrapping up the interview.

What, then, is a gesture? Sfard (2009) defined it as "a body movement fulfilling communicational function" (p. 194). Under this definition, all body movements — whether walking to the back of the classroom, tilting one's head, shifting one's gaze, or moving one's hands up and down while verbally recounting a story — are gestures. While we find value in this definition, we instead defined gestures more narrowly as an 'arm, hand, and/or gross whole body movement used to communicate disciplinary content, whose meaning was cued or complemented by verbal speech or other modes.' This narrower definition of gesture enabled us to develop a classification scheme that we used to classify and count teachers' purposeful hand and body movements in each discipline (see Methods section).

\section{Discipline-Specific Uses of Gestures}

Speakers tend to gesture more when communicating spatial versus non-spatial information (Alibali, 2005; Krauss, 1998). Moreover, gestures are more effective at conveying information about concrete, observable phenomena, rather than information about abstract concepts (Hostetter, 2011). Because many subjects in earth science are concrete rather than abstract in the sense that they emphasize physically tangible or measurable phenomena (Bazerman, 1988), and because earth science is especially dependent on spatial reasoning (Orion \& Ault, 2007), we hypothesized that gestures would be especially important in earth science as compared to other disciplines.

Roth and colleagues (e.g., Pozzer-Ardenghi \& Roth, 2005; Roth \& Bowen, 2000; Roth \& Welzel, 2001) addressed the role of gestures in science and particularly in the earth sciences, confirming that they often communicate spatial information in this discipline, either in 
conjunction with verbal speech or with several other modes. For instance, Roth and Lawless (2002) described a teacher who gestured over a landscape photograph in order to point out the confluence of two tributary rivers, eventually moving her hands from the photograph out into three-dimensional space to demonstrate "funneling" and "coming down." In this case, the gestures enabled the visual perception of movement into three-dimensional space, affordances not offered by the photograph alone.

Along with affirming gestures' aptness at depicting the spatial orientation of concrete phenomena, Roth et al.'s work also underscores the importance of gestures' function as a type of "glue" that holds together the content of other modes. For example, the teacher who stated "this river" used a pointing gesture to connect her spoken explanation to the relevant part of the image (Roth \& Lawless, 2002). Other researchers (Goodwin, 2000) have likewise argued that pointing or tracing gestures “index, construe or treat as relevant or irrelevant, entities in the participants' surround[ings]" (p. 1489; cf. Wells, 2000) during scientific activity. In all, then, gestures may be central to earth science for at least two reasons: their ability to represent relevant aspects of concrete phenomena, such as their changing spatial position, and their ability to work in conjunction with verbal speech to call attention to specific aspects of other modes.

In the discipline of mathematics, a growing body of research (e.g., Lemke, 2003; Radford, 2009) has likewise advanced the idea that gestures often play a central role in communicating disciplinary concepts. As in earth science, this research suggests that the discipline of mathematics tends to rely on particular types of gestures. Several studies have pointed toward the importance of gestures' ability to communicate the visual appearance of mathematical objects, such as shapes and slopes on line graphs (Arzarello, Paola, Robutti, \& Sabena, 2009; Yoon, Thomas, \& Dreyfus, 2011). 
Gestures in mathematics are also frequently used to point students' attention toward other representations, such as specific components of numeric/symbolic combinations and graphs (Bjuland, Cestari, \& Borgersen, 2008). Valenzeno, Alibali, and Klatzky’s (2003) research indicated that this latter type of gesture can be especially vital to students' understandings of mathematical concepts by linking verbal speech to visible objects (cf. Flevares \& Perry, 2001). In synthesizing the findings across several studies on gestures in mathematics, Sfard (2009) concluded that "gestures are crucial to the effectiveness of mathematical communication... [because] gestures are invaluable means for ensuring that all the interlocutors 'speak about the same mathematical object"' (p. 197). In other words, a number of studies seem to suggest that gestures' ability to connect verbal speech to other modes is especially important in this discipline.

Many reports that synthesize the role of gestures in classroom instruction (e.g., GoldinMeadow, 2004; Roth, 2001) have tended to focus more on the disciplines of science and mathematics than language arts and social studies. Nonetheless, gestures can play a vital role in communicating the humanities as well (Neill \& Caswell, 1993). McNeill and colleagues (Cassell \& McNeill, 1991; McNeill, 1992)—although their research did not address classroom communication per se — studied people's gestures as they orally recounted animated tales they had watched, an experiment that was later repeated by several other researchers (e.g., Alibali, Heath, \& Myers, 2001; Beattie \& Shovelton, 2002). In addition to reiterating that speakers gesture more when communicating spatial information, the authors found that character viewpoint gestures - or gestures wherein the communicator's hands, arms, and body represent those of a character in the story_-significantly aided listeners' ability to understand and remember narratives. 
Embodying texts from a character viewpoint can be a form of drama, which has historically played a central role in English curricula (Applebee, 1974). Franks, Durran, and Burn (2008) echoed the importance of the role of drama in contemporary English classrooms, arguing that character-viewpoint gestures, as enacted through drama, engender enriched aesthetic, emotional, and cognitive engagement with literature. Schneider, Crumpler, and Rogers (2006) also recommended character-viewpoint gestures in social studies instruction in order to engender empathetic perspectives toward historical and contemporary figures. Characterviewpoint gestures may thus be especially appropriate to disciplinary communications in language arts and social studies.

Although a growing body of research has addressed gestures' role in classroom instruction, the vast majority of these studies have analyzed gestures in individual lessons or in individual instructional units. In contrast to these previous studies, we documented six teachers' gestures as they taught two different content areas throughout the course of one school year. We therefore expanded on the existing body of research by identifying how the communicative demands of each discipline shaped gestures over time, leading to stable gestural patterns specific to each discipline. Observations of gestures over this duration of time enabled us to respond to our research questions by (a) describing discipline-specific patterns of gestures that recurred throughout the year; and (b) describing the role that the gestures played in realizing each discipline.

\section{Method}

To this end, we conducted multiple case study research (Stake, 2006), which is useful for examining a "phenomenon... of which we might seek examples to study" (p. 6). According to Stake, this approach necessitates a shift from understanding each case as a whole to developing 
in-depth understandings of one phenomenon — in this instance, instructional gestures - across multiple cases. We purposively selected six middle school teachers in the Southeastern United States to participate in this study for two reasons. First, their colleagues and administrators recommended them as exemplary teachers due to their innovative teaching and high end-of-year test scores. We established this criterion with the hope that their use of gestures would provide insights into ways that effective teachers communicated their respective disciplines. Second, they were selected because they were each highly qualified to teach two disciplines. The purpose of this criterion was to enable descriptions of how even the same individual exhibited different gestural patterns according to discipline. All participants' names have been replaced with pseudonyms to protect their confidentiality.

\section{Data Collection}

Three types of data were used to answer the two research questions. Field notes, the first source of data, were written during observations of 354 total lessons, ranging between 50 and 90 minutes in length (see Table 1), with each teacher receiving roughly an equal number of observations in each content area. The field notes focused primarily on describing the types of gestures used in the classroom. The observer wrote detailed notes for the first time each gesture type appeared, adding as much detail as possible for other gestures used throughout the instructional episode and fleshing out the notes when the teacher was not gesturing. Although this level of description did not enable certain nuances of analysis, such as the specific distance of the gesture from the communicator's body (Beattie \& Shovelton, 2002), it did allow for us to code gesture type by describing how each type of gesture was used in each instructional episode.

Insert Table 1 about Here 
The second source of data was 151 video clips, averaging 7.4 minutes each, taken of the teachers' instruction throughout the school year. The teachers selected several lesson segments to be videotaped because they believed these segments depicted effective instruction. The observer selected other segments to be videotaped when the teachers began to provide verbal explanations that included the use of gestures. Lastly, each teacher was interviewed for 25-60 minutes four to nine times throughout the school year at regular intervals. These interviews addressed topics such as teachers' use of gestures, their use of other representations, and their perceptions of their disciplines. This final source of data was not formally analyzed but instead served as contextualizing information for the study.

\section{Data Analysis: Phase One}

The first phase of data analysis relied on modified constant comparative analytic methods (Corbin \& Strauss, 2008). We responded to the first research question, What discipline-specific patterns of gestures were noticeable in the teachers' instruction?, by identifying how often particular types of gestures appeared in each discipline. To accomplish this task, we read existing gestural classification schemes (e.g., Efron, 1941; McNeill, 1992; Wundt, 1973), and we discussed the degree to which these existing definitions of gestures cohered with the data. We also read through all data points that had been assigned the code of gesture and employed the "major analytic strategies... of asking questions and making comparisons" (Corbin \& Strauss, 2008, p. 199) in order to identify specific properties of subcategories that fit under the main category, type of gesture.

To develop these subcategories, we read through randomly-selected field notes and video transcriptions and noted similarities and differences across gestures, which cohered to some 
extent with existing gestural classification schemes. For instance, iconic gesture is a major category in McNeill's (1992) gestural classifications. This term is used to apply to gestures that represent observable aspects of a concrete object, event, action, or phenomenon expressed in speech, such as using both hands to hold onto an imaginary piece of paper while saying "holding onto blueprints" (p. 99). After a very large number of gestures had been designated iconic, we decided that this code did not provide a nuanced view of how gestures were used in different disciplines, and we consequently developed categories that could be considered subcategories of iconic gesture, such as the following:

- Action gestures (what Wundt termed mimic gestures), coded when the arms or hands mimicked an observable physical act performed by an organism (e.g., putting hand in a fist and pushing down several times while narrating an account of a soldier tamping down gunpowder in a gun barrel);

- Magnitude gestures, coded when the arm/hands represented a large or small distance, a small or large size, or a small or large amount (e.g., stretching arms out as far as possible and saying "the sun is going to be way bigger than our classroom" as students made a scaled model of the solar system);

- Movement gestures, coded when the arm/hands represented an observable entity or entities going from one point to another, with a relative emphasis on direction, speed, or spatial position of the entity's (entities') starting point relative to its (their) ending point (e.g., moving one hand around a stationary hand to represent the revolution of the earth around the sun);

- Shape gestures, coded when the arm/hands indicated the physical outline of a form or figure (e.g., putting middle fingers and thumbs together to form an outline of a circle); 
- Spatial position gestures, coded when the arm/hands indicated an observable entity placed in a specific location relative to another observable entity (e.g., using the stationary left fist to represent the earth, and placing the right hand, palm flat, above the left fist, first closer to the left fist, and then progressively farther away, while describing the relative spatial position of the different layers of the atmosphere).

Pointing gestures, or deictic gestures, have also been a key category in many gestural classification systems (e.g., Efron, 1941; Ekman \& Friesen, 1969); we coded gestures as pointing only if the speaker used the arm/hand to draw attention to a sub-component of another mode. Other types of gestures included distinction gestures, classified when the arm/hand was used to separate one category or observable entity from others (e.g., lifting the left hand every time a student named a renewable resource and the right hand every time a student named a nonrenewable resource in a whole-class discussion) and metaphoric gestures, or gestures wherein the arm/hand represented some aspect of an abstract concept (e.g., moving index finger in a circle to represent the concept of whole).

We also used modified constant comparative analytic methods to provide a starting point for answering our second research question, What role did gestures play in the realization of each discipline? To this end, we identified how often gestures were used in each discipline as compared to other modes, such as images or writing. We hoped that this classification scheme would begin to enable us to draw global inferences about gestures' overall significance in each discipline. For instance, if gestures appeared with three times more frequency than any other mode in one discipline, then this finding (coupled with the results from other types of analysis) would support the assertion that gestures played a central role in communicating disciplinary concepts. 
To identify how often gestures were used in each discipline as compared to other modes, we used an existing modal classification scheme (Wilson, 2010) to inform our understanding of patterns in the current data set. During this second iteration of constant comparative analysis, supporting categories included images, with subcategories such as maps and video; non-iconic visuals, with subcategories such as numbers/symbols and graphic organizers; three-dimensional objects, with subcategories such as models and geometric solids; and written words, with subcategories such as multiple-choice questions and instructions.

After we tested the codes on randomly selected data, one author coded the entire data set while another author coded $10 \%$ of the data by reading written transcripts from field notes, as well as transcripts of the videos that included images accompanied with written transcripts of teachers' verbal speech. We achieved over $85 \%$ agreement in the codes that we assigned to gestures and other modes, an indicator that our codes were reliable (Lincoln \& Guba, 1985). The teachers also confirmed that our frequency counts resonated with their own perceptions of their instruction.

Prior to coding, we split the field notes into instructional episodes (Siskin, 1994), which were delineated by (a) a shift to a different instructional activity, and/or (b) a new social configuration in the classroom such as a shift from whole-class instruction to group work. For each instructional episode, a particular type of gesture or mode was counted only once. For example, although a mathematics teacher may have pointed ten times during one verbal explanation of a numeric/symbolic text, we counted gesture: pointing once during that instructional episode.

\section{Data Analysis: Phase Two}


Although the first phase of data analysis enabled us to identify the frequency with which gestures were used in relation to other modes in each discipline, it did not provide insight into how gestures afforded the communication of particular types of content. Consequently, the second phase of data analysis sought to address the second research question by identifying the roles that gestures assumed in relation to other modes within specific communicative stretches. Whereas the first phase of the analysis entailed a macro-analysis of how gestures were used over time, this second phase of analysis entailed a micro-analysis of how gestures were used in particular instances.

To this end, two authors analyzed video segments using a modified multimodal concordance chart (Baldry \& Thibault, 2006). We analyzed one video clip per every ten instances that a type of gesture appeared in the data set. For example, because pointing gestures were used in 70 instructional episodes in mathematics, we analyzed seven instances in which mathematics teachers used pointing gestures. Each column of the multimodal concordance chart followed a single mode as it was used throughout the lesson segment, while each row was delineated by phases, defined as "copatterned semiotic selections that are codeployed in a consistent way over a given stretch of text" (p. 47). For example, if a teacher said "this" in verbal speech while pointing to a number, the three modes (speech, gesture, and number/symbol) were split into one phase because they were co-deployed toward a similar communicative end. (See Figure 1 for an analysis of one phase). Within each phase, each mode was analyzed individually and collectively in order to understand gestures' role within the larger act of communication.

Insert Figure 1 about Here 
The multimodal concordance charts also enabled us to identify whether gestures played a relatively important or subordinate role relative to other modes in each act of communication. We used two criteria to determine whether a gesture was important or subordinate in the context of particular messages. First, we determined whether the gesture was "redundant" (Crowder, 1996; Hostetter, 2011) in the sense that it contained "no new information to that already expressed in accompanying verbal language" (Crowder, p. 182). In one instructional episode, for example, May slowly moved her hands, palms down and fingers wiggling, from her upper chest to the lower sides of her body, as she said, "You know how that shield volcano is made from that slow moving stuff." In this case, the gestures and words both represented the common referent shield volcano. They both communicated one aspect of this referent: the relative speed of its lava flow. Only the gesture, however, represented the shape of its gentle slope. By examining how each mode did or did not uniquely represent aspects of a given referent, we identified disciplinespecific patterns of gesture use wherein gestures provided specific types of unique, or nonredundant, information in each communicative act.

From another perspective, no gesture is entirely 'redundant' or superfluous (Birdwhistell, 1970). Because each mode is characterized by a unique set of physical properties, the type of communication it affords is also unique, and gestures offer visual depictions of referents as opposed to verbal descriptions of them. For this reason, a second criterion was also used to determine whether gestures played a major or minor role in individual acts of communication: The authors determined whether or not the teacher's message was cohesive, coherent, and complete without them (Bezemer \& Kress, 2009; Norris, 2009). For instance, May’s verbal statement, "divergent tectonic plates move like this," was not cohesive without the accompanying gesture of two hands moving apart. By contrast, the verbal statement, "and so [the 
garbage] piled up toward the ceiling," a line read aloud from Silverstein's (1974) poem "Sarah Cynthia Sylvia Stout," was cohesive without Alice's accompanying gesture of lifting her arm up to indicate the magnitude of the garbage pile.

In addition to identifying how gestures contributed unique information in terms of the ideational metafunction of communication, we also sought to identify how gestures played textual roles in the second phase of the analysis. In the context of a multimodal concordance chart, the textual function of communication connects different modes to each other within the same phase, and it connects the current phase to previous and forthcoming phases. For instance, Tami had created a table indicating place value (e.g., ones, tenths, etc.), pointed to one column of the table, and asked her students, "What's this place value?" In this act of communication, the pointing gesture served an important textual function by connecting Tami's verbal speech to a specific point on the table, without which, the message would have been incomplete. By analyzing how gestures connected different modes, fulfilling a textual function, we identified an additional way in which gestures contributed to individual acts of communication in particular disciplines.

\section{Data Analysis: Phase Three}

The analyses from Phases One and Two were limited in the sense that we wanted to make inferences about how gestures were used across a whole discipline, yet the multimodal concordance charts provided snapshots of how they were used in specific instances of instruction. Phase Three was intended to address this problem by connecting the analyses conducted in Phases One and Two.

In Phase One, the data had all been coded and uploaded into a qualitative data analysis computer software package that allowed for the easy retrieval of data that had been given the 
same code. When the authors called up the discipline of earth science, for example, and typed in movement, a list of all of the instances that had been coded as movement gestures in earth science, including photographs, appeared onscreen. After coding several instances of movement gestures in Phase Two of the analysis, the authors noted certain properties. For instance, in terms of the ideational function of communication, the movement gestures referred to physically tangible entities or phenomena (e.g., wind, molecules, sound waves, tectonic plates) and communicated properties of those phenomena that were not communicated through other modes in that particular lesson segment.

Prior to writing the section about gestures in each discipline (e.g., movement gestures in earth science), we retrieved the data with that code, scanned the resulting photographs and lesson segments, and compared them to our analysis from Phase Two. Although we discussed discrepant cases, the purpose of this study was to find how teachers commonly used gestures, and this type of general comparison of the codes in Phase One and the analysis from Phase Two enabled us to draw evidence-based inferences about how gestures were commonly used in a general sense within each discipline.

\section{Limitations}

Our research was limited in several ways. All six teachers identified themselves as being middle class and White, but research has suggested that gestures can vary depending on the culture of the communicator (Kendon, 2004). Although these teachers were considered to be successful at communicating disciplinary concepts to their culturally diverse students, this study does not enable a discussion of how people with different cultural, geographic, and linguistic backgrounds might have used gestures to meet the needs of a particular group of learners (e.g., Church, Ayman-Nolley, \& Mahootian, 2004). Rather than theorizing modes in terms of the 
students' or teachers' cultures, therefore, this study theorizes modes in terms of disciplinary practices, which does not account for how people with different cultural practices might have enacted the disciplines described in this study.

Another potential limitation included unequal numbers of observations for each teacher due to a variety of scheduling difficulties, such as a school-wide rotating schedule that changed with fewer than eight hours advanced notice. Because the purpose of this qualitative study was not to prove statistical difference, but rather to describe teachers' use of discipline-specific gestures, we believe that even the teacher who was observed the fewest number of times due to the rotating schedule provided a sizeable body of data from which we could identify general disciplinary trends in gestures.

Finally, this study was also limited in its focus on teachers' gestures without a concurrent focus on students' gestures. Wells (2000) and others (McDermott, Gospodinoff, \& Aron, 1978) have studied teachers' and students' gestures in small-group settings, illustrating how teachers' and students' body movements (e.g., gaze, position, pointing) respond to specific shifts in each other's body movements, such as when a student orients his body position toward a book and gazes down at it after a teacher's gaze indicates to him to get back on task. This almost exclusive emphasis on teachers' gestures did not enable us to provide a nuanced description of teacher gesture as a response to students' previous embodied movements. Rather, we viewed teachers' gestures primarily as representations of disciplinary content.

Because we excluded student gestures and classroom management gestures from Phase One of the analysis, we believed we did not have enough data to draw warranted conclusions regarding how gestures were used to fulfill the interpersonal function of language, including how teachers used gestures to realize particular types of roles in relation to students. Consequently, 
the discussion section focuses more on aspects of the ideational and textual roles of disciplinary gestures, rather than on their potential role in realizing particular social roles between teachers and students.

\section{Findings}

Our analyses responded to our initial research questions by identifying (a) patterns of gestures unique to each discipline and (b) discipline-specific roles that gestures played in disciplinary communication. In response to the first research question, Tables 2 and 3 illustrate that, relative to all gestures used in each discipline, the percentage of gestural type varied in discipline-specific ways. Below, we describe the gestural patterns that appeared in each of the four disciplines. Specifically, each section responds to our research questions by (a) elaborating on discipline-specific patterns of gestural types, and (b) identifying the role that gestures tended to play relative to other modes in that discipline. We chose specific examples from the data set to describe below because they were 'telling cases' (Rex, 2001) that illustrated patterns present across the data set as a whole, as suggested by Phase Three of the analysis.

Insert Tables $2 \& 3$ about Here

\section{Earth Science}

As indicated by Table 3, movement gestures were the most common type of gesture in the three teachers' earth science instruction. In some instances of communication, movement gestures communicated more aspects of the referent than verbal speech, which served primarily to label the gestures. For example, in one instructional episode, Grace explained the movement of sound waves through different types of matter: 
So, gases [arms lifted and spread wider than body], sound travels like this [touches forearms together and then separates them widely again, repeats motion slowly moving arms from left to right]. Liquid [arms lifted about a foot apart], it's like this [touches forearms together and then separates them about a foot apart again, repeats motion more quickly while moving arms from left to right]. Solid [arms lifted about an inch apart from each other], it's like this [bangs forearms and fists together very quickly and moves arms from left to right].

In this example, Grace's speech served to label the gestures, which alone represented relative wave number (number of times the forearms hit each other in the same stretch of time relative to other mediums); relative wave length (distance between the forearms for each of the three mediums); and relative speed. The three teachers also used verbal speech to label gestural information when describing tectonic plate boundaries. For instance, May asked students to "show me a transform boundary." After students had demonstrated the boundaries through gestures, May used her palms, each of which represented a tectonic plate, to demonstrate a particular type of movement (e.g., palms flat and facing down, sides of index fingers aligned and rubbing back and forth against each other). In all, 69\% of movement gestures in earth science worked in tandem with verbal speech alone, as in these examples.

The remaining $31 \%$ of movement gestures worked in conjunction other modes, each communicating unique aspects of various phenomena. Figure 2 illustrates how Grace used gesture, speech, and image to explain lunar phases. Grace first pointed to the new moon on the diagram and moved her hand in a counterclockwise motion around the earth (shown in Figure 2) until it reached the full moon. She then pointed to the moon at different locations as it moved from the new moon to the full moon position, asking students to name each type of moon. 
Throughout this communicative stretch, only the gestures indicated the directionality of the moon's orbit (e.g., the moon moves counterclockwise around the earth); only the images represented the specific shape of the moon at each point in the lunar cycle (e.g., half of a circle was visible); and only the written or spoken words labeled each moon (e.g., new moon; crescent moon) and labeled its overall telos at different points of the cycle (e.g., waxing or waning). As in these examples of gestures, across all coded instances from Phase Two and Three, movement gestures in earth science were non-redundant to other modes in the sense that they exclusively communicated one or more aspects of the focal phenomenon. Consequently, a student who did not attend to the information in gestures would have missed information about the referent in that lesson segment.

\section{Insert Figure 2 about Here}

Pointing gestures, the next most common type of gesture across all three teachers' earth science instruction, similarly played a unique function in the communicative episodes in which they were used, rendering these communications incomprehensible without them. Pointing gestures in earth science related verbal speech to other modes: $46 \%$ of pointing gestures connected speech to three-dimensional objects, while 39\% of pointing gestures connected speech to images. For example, teachers pointed to specific lines on rocks and asked students what caused those lines; they pointed to specific parts of globes and asked which season a person "here" would experience if the sun were at a certain location relative to the globe; and they drew students' attention to specific parts of images, such as pointing to one country on a moving map 
of the continents to show how it moved from its presumed position in Pangaea to its location today.

In these individual acts of communication, the teachers' verbal speech, such as "Why would it be hotter here than there?," did not comprise a complete message without another mode (e.g., a globe) and the pointing gestures that connected them. In this sense, whereas movement gestures were valuable in part due to their ideational function, or their ability to represent specific information about their referent, pointing gestures were essential primarily due to their textual function as they related different aspects of the message to each other.

Spatial position gestures were the third most common type of gesture used in earth science, comprising over one tenth of all gestures. Unlike movement gestures, which showed an entity's position at one point in time as compared to another point in time, spatial position gestures depicted spatial relationships that were fixed at one point in time. Because images and three-dimensional models were readily available, each teacher more frequently pointed to these modes to indicate relative spatial positions, which afforded a relatively permanent view as compared to spatial position gestures alone.

Nonetheless, spatial position gestures in this discipline at times held affordances not offered by many available images. For instance, Grace asked her students to lift their right hands about a foot in front of their faces, palms flat, and to put their left fisted hands between their faces and the flat palms. She told students that their heads represented the earth, their right hands represented the sun, and their left hands represented the moon, and she asked students to name the type of eclipse represented by their hands. As compared to many images that depicted the earth, moon, and sun as circles_-presumably from a vantage point out in space — this type of 
representation enabled students to visualize a solar eclipse from the vantage point of the earth represented by their heads.

As this example demonstrates, gestures' inherent grounding in the body enabled the students to begin with a point of visualization that was not afforded by many other iconic representations. In a discipline that requires visualizing phenomena from different physical angles (Kastens \& Ishikawa, 2006), the vantage point offered by embodied movements may be an especially important affordance. In this way, spatial position gestures served an important ideational function — not necessarily because they represented unique spatial information about their referents as compared to other modes (e.g., an image of a solar eclipse)—but because they could afford the visualization of the same spatial information through an embodied vantage point.

\section{Mathematics}

Whereas gestures in other disciplines were more varied, mathematics was the discipline wherein only one type of gesture, pointing, comprised a majority of total gestures in each of the three teachers' instruction (approximately 60\%). These deictic gestures appeared over three times as often as the next most common type of gesture, which communicated shape. As in earth science, pointing served an essential textual function, connecting speech to other modes, most commonly (56\%) numeric symbolic combinations. Pointing in mathematics was used in at least three ways: (a) to draw attention to specific components of one mode; (b) to provide a point-bypoint mapping of connections across modes; and (c) to represent mathematical operations and actions.

Much of teachers' verbal discourse drew students' attention to observable representations as teachers pointed to specific aspects of them, such as specific decimal points, specific points on 
graphs, specific digits within written numerals, or specific vertices on three-dimensional objects. Examples of verbal speech that accompanied pointing included: What place value is this?; What does this mean [pointing to a letter within a formula]? This means 12 to the second power or 12 squared [pointing to $12^{2}$ ].; What's this shape [pointing to a face of a three-dimensional object]? In each example, pointing drew students' attention to one component of a visually perceptible representation, enabling further discussion and comprehension of that component.

Unlike in language arts, wherein written words were a more prevalent mode (see Table 1), numerals' prevalence in mathematics required that teachers employ a different method of calling students' attention to specific parts of this mode. Because a single digit (e.g., 2) could appear multiple times in the same expression, equation, or table, and because it would be difficult to refer to a face of a three-dimensional shape as "top" or "bottom," pointing was required in this discipline to ensure that all students were talking about the same 2 , the same face, and so forth - a feat that was not easy, or even possible, to accomplish through verbal language alone.

Pointing served a second function by mapping out point-to-point connections across modes, such as physically showing students how one point on a numeric table (e.g., $\mathrm{x}, \mathrm{y}$ ) responded to one point on a line graph; how one face of a three-dimensional rectangular prism corresponded to one component of a numeric/symbolic formula for finding surface area; how negative and positive integers, written as numerals, corresponded to certain points on a number line; how specific fractions corresponded to different lengths of lines on a customary ruler; and more. Teachers' pointing gestures mediated connections across modes by showing how specific points within one modal system (e.g., numbers/symbols) corresponded to specific points of another modal system (e.g., images, lines on a ruler). 
Pointing also represented various types of mathematical action. For example, in lessons on how to convert across different units in the metric system, Tami and her students both used pointing to move imagined decimal points from one place value to another, representing the act of multiplying or dividing by ten. Grace and her students similarly pointed to different points on number lines to represent addition as they performed actions such as "moving to the left five places" to add a negative five. As in these examples, pointing did more than call students' attention to aspects of different modes; it also represented mathematical operations, such as addition and multiplication.

Although all three teachers' curricula addressed geometric concepts, shape gestures represented only $10 \%$ of total gestures. Moreover, in $97 \%$ of instructional episodes that included shape gestures, shape gestures were used to trace another representation, such as an image or three-dimensional object. One example of 'shape with speech' (no other modes included) will illustrate why teachers did not use shape gestures more often.

While Grace's students were solving a word problem requiring them to find the surface area of a rectangular prism, Grace said, "We need to make the sides [puts two hands, palms flat and facing each other, as though they were placed on the sides of a box], and the top and the bottom" [moves palms flat, facing each other, as though they were placed on the top and the bottom of the same box]. Then, to show how this rectangular prism related to a pyramid, Grace said, "This side would be tilted in; this side would be tilted in; this side would be tilted in; and this side would be tilted in." As she said "this side would be tilted in," she moved a flat hand, palm vertical, and tilted it inward toward an imagined apex extending from the four sides of the imagined rectangular base. 
In other lessons, Grace's students used nets to build rectangular prisms and pyramids, comparing the original flat shapes to the final three-dimensional products. The relative permanence of these latter modes afforded more precise visualizations than gesture, enabling teachers and students to point out and discuss various aspects of visible shapes such as their angle relationships, whereas shape gestures were comparatively transitory and imprecise. Thus, while shape gestures at times communicated unique information conveyed by no other mode, more often, three-dimensional objects or geometric shapes more aptly afforded the precision of visualization required by the discipline of mathematics. Accordingly, teachers usually preferred pointing to images to communicate shape, rather than using shape gestures by themselves.

\section{Language Arts and Social Studies}

On the whole, gestures were used less frequently in language arts than in earth science, mathematics, and social studies. Despite this difference in frequency, gestures in language arts and social studies were similar in other regards. For instance, action gestures appeared either as the first or second most common type of gesture in both the language arts and social studies teachers' instruction as they mimicked the actions of historical figures or literary characters. We identified that $80 \%$ of instances coded as action gestures in language arts and social studies were 'non-essential' in the sense that these gestures were not required in order for the communication to be a coherent message; they did not communicate information that was non-redundant to other modes; and/or they did not directly contribute to the teachers' instructional objectives. For instance, in a lesson on techniques used in poetry, Alice read a poem about basketball, displayed illustrations of girls dribbling a ball, and said, "Dribble dribble swish," moving a hand, palm flat, up and down as though she were dribbling a basketball. She then asked students to identify the literary techniques used in the excerpt. 
Although this action gesture could perhaps contribute new information to somebody who did not know what the spoken word dribbling meant, such as English learners, it did not contribute to the instructional objective of understanding onomatopoeia or repetition. (No English learners attended this particular class.) Moreover, the visual appearance of 'dribbling' was communicated through the illustration. Although the use of gestures arguably engages listeners more than speech without gestures (Kelly \& Goldsmith, 2004), many of the action gestures in language arts and social studies were similar to this one in the sense that students could have achieved the teachers' instructional objectives without them.

In addition to action gestures, pointing gestures were prominent in social studies, $52 \%$ of which drew students' attention to specific locations on maps. Language arts teachers' pointing gestures, in contrast, were most commonly used (54\%) to point to words within a written text. Unlike in mathematics, where the mode of numbers/symbols required precise attention to specific digits and wherein pointing gestures were essential to producing coherent messages, pointing gestures in language arts and social studies were more likely to be more ambiguous.

Alice, for instance, displayed a close-up photograph of a damaged statue and said, "So [acid rain is] damaging buildings, like for example this statue right there [waves hand over statue], that's what happening to it because of air pollution. It's eating through the stone." In this example, the pointing gesture was meant to draw students' attention to the photograph in general, but the damage on the statue was evident without pointing. Likewise, language arts teachers at times waved their hands over lists their students had generated on the board, pointed to titles of poems, and drew their students' attention to other texts in ways that were also evident through teachers' verbal speech, even without pointing. 
Distinction, a third type of gesture, was also prominent in Annette's English instruction as she distinguished among conceptual groupings. For instance, Annette's students read a fable contrasting the lives of dogs to wolves, claiming that the former lived lives with security and constraints whereas the latter lived lives with uncertainty and freedom. The students then wrote essays about which lifestyle was better. As they were discussing the differences in these lifestyles, Annette repeatedly stuck her left hand to the far left of her body whenever she or her students named concepts associated with dogs, whereas she stuck her right hand to the far right of her body whenever she or her students named concepts associated with wolves.

We categorized this type of gesture as serving a textual function because it showed interrelationships among concepts - in this case, by emphasizing which concepts were similar (e.g., all concepts that earned a left hand designation) and which were different (e.g., concepts that earned a right hand designation versus those that earned a left hand designation). Alice and May, rather than using distinction gestures to communicate conceptual differences in their language arts curricula, more commonly used graphic organizers and transition words in verbal speech, suggesting that conceptual differences can be represented via many modes, including but not limited to gesture.

In sum, in individual instructional episodes in language arts and social studies, gestures played various textual roles (primarily through demonstrating connections across ideas or through drawing students' attention toward other modes) and ideational roles (primarily through mimicking people's actions). Often, however, the gestures did not directly communicate new information in relation to teachers' instructional objectives.

\section{Discussion}

We return to our original research questions, which asked what gestural patterns were 
evident in the teachers' instruction and what role gestures played in the realization of each discipline. First, we assert that gestures played an important ideational role in earth science by non-redundantly communicating aspects of their referent: an ever-changing, physically observable earth. Just as Bazerman (1988) asserted that the sciences address physical phenomena and value human action only insofar as this action can contribute to understandings of physical phenomena, we found that gestures' roles in earth science were first to represent concrete phenomena and only secondarily to mimic human action in the process of coming to know those phenomena.

Throughout the study, $90 \%$ of the earth science teachers' essential questions, or questions stating the instructional objective for the day, related to moving physical phenomena, such as How does the relative position of the earth, moon, and sun affect us?, How do weathering and erosion affect the earth's surface?, How are tornadoes and hurricanes similar and different? and What causes lunar phases?. Because gestures' affordances enable them to represent observable entities (e.g., rain) more fully than abstract concepts (e.g., democracy) (Hostetter, 2011), we argue that this mode was especially important to teachers' instantiation of this discipline.

To be sure, gestures played an ideational role in all disciplines in the sense that they represented physically observable referents. In language arts, however, only $1 \%$ of the teachers' essential questions addressed an observable object in the natural world. The rest of essential questions were focused on approaches to reading and writing (How can we determine the meaning of unfamiliar words? What can I do to engage my readers?) and on characters' psychological motivation (How does pride affect Daphne, Apollo, and Arachne?).

Essential questions in language arts were not focused on objects' or characters' physical characteristics or relative spatial positions. Accordingly, gestures played a relatively minor role 
in this discipline, as indicated by May's instruction wherein she used gestures over three times as often in earth science as she did in language arts. Gestures' role in this discipline was often to mimic characters' actions, but these actions were usually not essential to reaching teachers' objectives (identifying literary techniques) in the same way that gestures in earth science communicated non-redundant information about the characteristics and causes of physical phenomena.

In social studies, a regular ideational role of gestures was likewise to mimic people's actions. Common essential questions, such as What reasons led to the American Revolution?, could be answered with both physically tangible responses (e.g., British soldiers invading Patriots' homes) and more abstract ideological responses (e.g., no taxation without representation). In a majority of instances, however, we classified gestures as playing a more peripheral role in reaching social studies teachers' objectives, in the sense that most acts of communication were cohesive without gesture, such as when Alice pretended she was turning a steering wheel while asking students about the effects of car emissions on the environment.

Although gestures served a textual role in all disciplines, in no discipline was this role more pronounced than in mathematics. Wertsch's (1998) description of tool mediation points toward possible explanations for why pointing gestures are especially important this discipline. He argued that physically tangible, semi-permanent representations (e.g., written numbers and symbols) are essential tools for performing mathematical operations. For instance, the spatial organization of base-ten numerals afford pattern matching in which numbers' syntax "is doing some of the thinking involved" (p. 29).

For this reason, problem solving arguably cannot be completed through speech and gesture alone. Because $86 \%$ of the mathematics teachers' essential questions entailed performing 
some type of mathematical action (e.g., How do I multiply and divide mixed numbers? How do I find surface area and volume?), much of teachers' verbal discourse drew students' attention toward the observable representations required to perform those actions. In addition to drawing students' attention toward these representations, teachers often used pointing to mediate between two or more different observable modal systems (e.g., images and numbers), showing how specific points within each modal system related to each other in a systematic fashion, a function of gestures that was observed to a lesser extent in earth science and was not observed at all in language arts or social studies.

\section{Implications for Instruction and Research}

A growing body of theoretical and empirical literature (Lee \& Spratley, 2010; Moje et al., 2008) has called for greater attention to the similarities and differences of representations and texts within and across disciplines, suggesting that understanding these characteristics is a necessary precursor to providing literacy instruction for students. This study suggests that, at least in some disciplines, gestures can be a central, regular form of communication, at times conveying information conveyed by no other mode. As part of their comprehension instruction, therefore, some teachers may have to explicitly teach their students how to attend to information in gestures, rather than treating gestural information as peripheral or non-existent, as is currently done in much of the available research and practitioner literature on comprehension instruction for disciplinary representations.

Previous theoretical literature (e.g., Alvermann, 2004) has suggested that comprehension strategies that often increase students' understandings of printed texts — such as asking clarification questions - can also improve students' comprehension of information presented largely through gestures and other multimodal mediums. Future empirical research can test these 
claims by noting whether comprehension strategy instruction, which has long been presumed to improve students' comprehension of printed texts, can also help students develop enhanced understandings of key information presented through gestures and accompanying modes. This research can also determine whether these approaches to comprehension instruction must be modified to account for the characteristics of these modes.

The National Reading Panel (2000), for example, recommended 'summarizing' as a key strategy that often improves students' comprehension. We wonder, however, what summarizing might entail after students learned about content through means that were not only verbal, but also profoundly embodied and gestural, drawing three-dimensional space into the 'meaning' of the representation. If teachers produce embodied modes because they afford the communication of particular types of content, then we hypothesize that students may likewise build and express enriched understandings of similar types of content when allowed to produce modes that draw on the affordances of bodies in space.

Because previous research (e.g., Wilson, 2011) has suggested that teachers do not often consider embodied modes as a legitimate means of assessment in classrooms, we call for more research on classroom instruction in which gestures are considered to be valued, legitimate, and essential modes through which learning occurs and through which learning is evaluated. Furthermore, because previous research (e.g., Kendon, 2004) has suggested that people from different geographic locations tend to use different types of gestures for different purposes, we also call for more research on how students may interpret instructional gestures differently depending on their backgrounds.

This research can also include explorations into the ways that gestures' misrepresentation of phenomena influence students' interpretations. For instance, although 
Grace's example of hitting forearms together communicated the relative speed at which sound moves through different mediums, it also misrepresented or ignored aspects of sound waves, such as peak-to-peak amplitude or sound intensity. Part of instruction on gestures - and indeed, all forms of representation — may therefore require discussions on how each mode miscommunicates or misrepresents aspects of its referent, thus working toward preventing misunderstandings .

Finally, this study also qualifies existing research literature in a different way. Although many disciplinary communications were incoherent without the use of gesture, in other lessons, gestures did not communicate non-redundant aspects of their referents, which were relevant to the teachers' instructional objectives. This study therefore suggests that treating gestural information as relatively peripheral may be valid depending on the specific act of communication, in contrast to previous assertions that gestures invariably enrich communicative effectiveness in educational settings (Goldin-Meadow, 2004). In this way, this study serves to qualify previous statements about disciplinary representations, calling attention toward instances wherein gestures play a major role in communicating disciplinary content as opposed to when they play a relatively minor role.

\section{Conclusion}

Unlike previous studies, which primarily examined teachers' use of gestures in individual lessons or units, this study describes teachers' use of gestures over the course of one school year, indicating that even the same teacher may use different types of gestures depending on the communicative demands of the discipline that he or she is teaching. Just as images (Rudwick, 1976) and words (Fang, 2006; Halliday \& Martin, 1993) are shaped in particular ways in order to meet discipline-specific communicative demands, gestures can also be shaped to meet the 
discipline-specific needs of communicators in earth science, mathematics, language arts, and social studies. The implications of discipline-specific uses for gestures have yet to be explored in research and pedagogical literature whose purpose is to help students understand disciplinary representations. However, because previous research has indicated that explicit comprehension instruction can increase students' understanding of printed texts, future research may be conducted regarding whether explicit comprehension instruction can help students understand disciplinary content communicated through gestures, especially in gesture-intensive lessons such as those often found in earth science. 


\section{References}

Alibali, M. W. (2005). Gesture in spatial cognition: Expressing, communicating, and thinking about spatial information. Spatial Cognition and Computation, 5, 307-331.

Alibali, M. W. Heath, D. C., \& Myers, H. J. (2001). Effects of visibility between speakers and listeners on gesture production: Some gestures are meant to be seen. Journal of Memory and Language, 44, 169-188.

Alvermann, D. E. (2004). Multiliteracies and self-questioning in the service of science learning.

In E. W. Saul (Ed.), Crossing borders in literacy and science instruction: Perspectives on theory and practice (pp. 226-238). Newark, DE: International Reading Association and National Science Teachers Association.

Applebee, A. N. (1974). Tradition and reform in the teaching of English: A history. Urbana, IL: National Council of Teachers of English.

Arzarello, F., Paola, D., Robutti, O., Sabena, C. (2009). Gestures as semiotic resources in the mathematics classroom. Educational Studies in Mathematics, 70, 97-109.

Baldry, A., \& Thibault, P. J. (2006). Multimodal transcription and analysis: A multimedia toolkit and coursebook with associated on-line course. London, UK: Equinox.

Bazerman, C. (1988). Shaping written knowledge: The genre and activity of the experimental article in science. Madison, WI: University of Wisconsin Press.

Beattie, G., \& Shovelton, H. (2002). An experimental investigation of individual iconic gestures that mediate their communicative power. British Journal of Psychology, 93, 179-192.

Bezemer, J., \& Kress, G. (2009). Visualizing English: A social semiotic history of a school subject. Visual Communication, 8, 247-262. 
Birdwhistell, R. L. (1970). Kinesics and context: Essays on body motion communication. Philadelphia, PA: University of Pennsylvania Press.

Bjuland, R., Cestari, M. L., \& Borgersen, H. E. (2008). The interplay between gesture and discourse as mediating devices in collaborative mathematical reasoning: A multimodal approach. Mathematical Thinking and Learning, 10, 271-292.

Cassell, J, \& McNeill, D. (1991). Gesture and the poetics of prose. Poetics Today, 12, 375-404.

Church, R. B., Ayman-Nolley, S., \& Mahootian, S. (2004). The role of gesture in bilingual education: Does gesture enhance learning? International Journal of Bilingual Education and Bilingualism, 7, 303-319.

Corbin, J., \& Strauss, A. (2008). Basics of qualitative research: Techniques and procedures for developing grounded theory ( $3^{\text {rd }}$ ed.). London, UK: SAGE.

Crowder, E. M. (1996). Gestures at work in sense-making science talk. The Journal of the Learning Sciences, 5, 173-208.

Efron, D. (1941). Gesture and environment. New York, NY: Kings Crown Press.

Ekman, P., \& Friesen, W. (1969). The repertoire of nonverbal behavior: Categories, originals, usage, and coding. Semiotica, 1, 49-98.

Erickson, F. (2004). Talk and social theory: Ecologies of speaking and listening in everyday life. Malden, MA: Polity Press.

Fang Z. (2006). The language demands of science reading in middle school. International Journal of Science Education, 28, 491-520.

Flevares, L. M., \& Perry, M. (2001). How many do you see? The use of non-spoken representations in first-grade mathematics lessons. Journal of Educational Psychology, $93,330-345$. 
Franks, A., Durran, J., \& Burn, A. (2008). Stories of the three-legged stool: English, media, drama from critique to production. English in Education, 40, 64-79.

Gibson, J. J. (1979). The ecological approach to visual perception. Boston, MA: Houghton Mifflin.

Goldin-Meadow, S. (2004). Gesture's role in the learning process. Theory into Practice, 43, $314-$ 321.

Goodwin, C. (2000). Action and embodiment within situated human interaction. Journal of Pragmatics, 32, 1489-1522.

Halliday, M. A. K. (1973). Explorations in the functions of language. London, UK: Edward Arnold.

Halliday, M. A. K. (1978). Language as social semiotic: The social interpretation of language and meaning. London, UK: Edward Arnold.

Halliday, M. A. K., \& Martin, J. R. (1993). Writing science: Literacy and discursive power. Pittsburgh, PA: University of Pittsburgh Press.

Hodge, R., \& Kress, G. (1988). Social semiotics. Ithaca, NY: Cornell University Press.

Hostetter, A. B. (2011). When do gestures communicate? A meta-analysis. Psychological Bulletin, 137, 297-315.

Hubber, P., Tytler, R., \& Haslam, F. (2010). Teaching and learning about force with a representational focus: Pedagogy and teacher change. Research in Science Education, 40, $5-28$.

Jewitt, C. (2006). Technology, literacy and learning: A multimodal approach. London, UK: Routledge 
Kastens, K. A., \& Ishikawa, T. (2006). Spatial thinking in the geosciences and cognitive sciences: A cross-disciplinary look at the intersection of the two fields. In C. A. Manduca \& D. W. Mogk (Eds.) Earth and mind: How geologists think and learn about the earth (pp. 53-76). Boulder, CO: Geological Society of America.

Kelly, S. D., \& Goldsmith, L. (2004). Gesture and right hemisphere involvement in evaluating lecture material. Gesture, 4, 25-42.

Kendon, A. (2004). Gesture: Visible action as utterance. Cambridge, MA: Cambridge University Press.

Kim, M., Roth, M-W., \& Thom, J. (2011). Children's gestures and the embodied knowledge of geometry. International Journal of Science and Mathematics Education, 9, 207-238.

Krauss, R. M. (1998). Why do we gesture when we speak? Current Directions in Psychological Science, 7(2), 54-60.

Kress, G. (2003). Literacy in the new media age. London, UK: Routledge.

Kress, G. (2005). Gains and losses: New forms of texts, knowledge, and learning. Computers and Composition, 22, 5-22.

Kress, G. (2010). Multimodality: A social semiotic approach to contemporary communication. New York, NY: Routledge.

Lee, C. D., \& Spratley, A. (2010). Reading in the disciplines: The challenges of adolescent literacy. New York, NY: Carnegie Corporation of New York.

Lemke, J. L. (1998). Multiplying meaning: Visual and verbal semiotics in scientific text. In J. R. Martin \& R. Veel (Eds.), Reading science: Critical and functional perspectives on discourses of science (pp. 87-113). New York, NY: Routledge. 
Lemke, J. L. (2003). Mathematics in the middle: Measure, picture, gesture, and word. In M.

Anderson, A. Saenz-Ludlow, S. Zellweger, S. Cifaerelli, \& V. V. Cifarelli (Eds.), Educational perspectives on mathematics as semiosis: From thinking to knowing (pp. 215-234). Ottowa, CAN: Legas.

Lim, F. V., O’Halloran, K. L., \& Podlasov, A. (2012). Spatial pedagogy: Mapping meanings in the use of classroom space. Cambridge Journal of Education, 42, 235-251.

Lincoln, Y. S., \& Guba, E. G. (1985). Naturalistic inquiry. Thousand Oaks, CA: Sage.

McDermott, R. P., Gospodinoff, K., \& Aron, J. (1978). Criteria for an ethnographically adequate description of concerted activities and their contexts. Semiotica, 24, 263-275.

McNeill, D. (1992). Hand and mind: What gestures reveal about thought. Chicago, IL: University of Chicago Press.

Melinger, A., \& Levelt, W. J. M. (2004). Gesture and the communicative intention of the speaker. Gesture, 4, 119-141.

Moje, E. B. (2008). Foregrounding the disciplines in secondary literacy teaching and learning: A call for change. Journal of Adolescent \& Adult Literacy, 52, 96-107.

National Reading Panel. (2000). Teaching children to read: An evidence-based assessment of the scientific research literature on reading and its implications for reading instruction. NIH Publication No. 00-4754). Washington, DC: National Institute of Child Health and Human Development.

Neill, S., \& Caswell, C. (1993). Body language for competent teachers. London, UK: Routledge. Norris, S. (2009). Modal density and modal configurations: Multimodal actions. In C. Jewitt (Ed.), The Routledge handbook of multimodal analysis (pp. 78-91). New York, NY: Routledge. 
Orion, N., \& Ault, C. R., Jr. (2007). Learning earth science. In S. K. Abell \& N. G. Lederman (Eds.), Handbook of research on science education (pp. 653-687). Mahwah, NJ: Lawrence Erlbaum.

Pozzer-Ardenghi, L., \& Roth, W.-M. (2005). Photographs in lectures: Gestures as meaningmaking resources. Linguistics and Education, 15, 275-293.

Radford, L. (2009). Why do gestures matter? Sensuous cognition and the palpability of mathematical meanings. Educational Studies in Mathematics, 70, 111-126.

Rex, L. (2001). The remaking of a high school reader. Reading Research Quarterly, 36, 288-314.

Roth, W.-M. (2001). Gestures: Their role in teaching and learning. Review of Educational Research, 71, 365-392.

Roth, W.-M., \& Bowen, G. M. (2000). Decalages in talk and gesture: Visual and verbal semiotics of ecology lectures. Linguistics and Education, 10, 335-358.

Roth, W.-M., \& Lawless, D. V. (2002). When up is down and down is up: Body orientation, proximity, and gestures as resources. Language in Society, 31, 1-28.

Roth, W.-M., \& Welzel, M. (2001). From activity to gestures and scientific language. Journal of Research in Science Teaching, 38, 103-136.

Rudwick, M. J. S. (1976). The emergence of a visual language for geological science, 17601840. History of Science, 14, 149-195.

Schneider, J. J., Crumpler, T., \& Rogers, T. (Eds). (2006). Process drama and multiple literacies: Addressing social, cultural, and ethical issues. Portsmouth, NH: Heinemann.

Sfard, A. (2009). What's all the fuss about gestures? A commentary. Educational Studies in Mathematics, 70, 191-200.

Silverstein, S. (1974). Where the sidewalk ends. New York, NY: HarperCollins. 
Siskin, L. S. (1994). Realms of knowledge: Academic departments in secondary schools. London, UK: Falmer Press.

Stake, R. E. (2006). Multiple case study analysis. New York, NY: Guilford.

Valenzeno, L., Alibali, M. W., \& Klatzky, R. (2003). Teachers' gestures facilitate students' learning: A lesson in symmetry. Contemporary Educational Psychology, 28, 187-204.

Van Leeuwen, T. (2005). Introducing social semiotics. London, UK: Routledge.

Wells, G. (2000). Modes of meaning in a science activity. Linguistics and Education, 10, $307-$ 334.

Wertsch, J. V. (1998). Mind as action. New York, NY: Oxford University Press.

Wilson, A. A. (2010). The nature of texts used in five academic disciplines. In R. T. Jiménez, V. J. Risko, D. W. Rowe, \& M. K. Hundley (Eds.), The 59th Yearbook of the National Reading Conference (pp. 154-170). Oak Creek, WI: National Reading Conference, Inc.

Wilson, A. A. (2011). Assessment as transmediation: Students reading and re-presenting across disciplines. Paper presented at the annual meeting of the American Educational Research Association, New Orleans, LA.

Wundt, W. (1973). The language of gestures. J. S. Thayer, C. M. Greenleaf, \& M. D. Silberman (Trans.). The Hague, NL: Mouton.

Yoon, C., Thomas, M. O. J., \& Dreyfus, T. (2011). Grounded blends and mathematical gesture spaces: Developing mathematical understandings via gestures. Educational Studies in Mathematics, 78, 371-393. 
Table 1

Background Information on Teachers and Number/Duration of Observations

\begin{tabular}{|c|c|c|c|c|c|c|c|c|c|}
\hline \multirow[t]{2}{*}{ Name } & \multirow[t]{2}{*}{ Education } & \multicolumn{2}{|c|}{ Earth Science } & \multicolumn{2}{|c|}{ Language Arts } & \multicolumn{2}{|c|}{ Mathematics } & \multicolumn{2}{|c|}{ Social Studies } \\
\hline & & $\begin{array}{l}\text { Years } \\
\text { Taught }\end{array}$ & $\begin{array}{l}\text { No. } \\
\text { Lessons } \\
\text { (time) }\end{array}$ & $\begin{array}{l}\text { Years } \\
\text { Taught }\end{array}$ & $\begin{array}{l}\text { No. } \\
\text { Lessons } \\
\text { (time) }\end{array}$ & $\begin{array}{l}\text { Years } \\
\text { Taught }\end{array}$ & $\begin{array}{l}\text { No. } \\
\text { Lessons } \\
\text { (time) }\end{array}$ & $\begin{array}{l}\text { Years } \\
\text { Taught }\end{array}$ & $\begin{array}{l}\text { No. } \\
\text { Lessons } \\
\text { (time) }\end{array}$ \\
\hline Alice & $\begin{array}{l}\text { BS, MA in English } \\
\text { education and social } \\
\text { studies endorsement }\end{array}$ & & & 11 & $\begin{array}{l}36 \\
50 \mathrm{~min} .\end{array}$ & & & 2 & $\begin{array}{l}30 \\
50 \mathrm{~min} .\end{array}$ \\
\hline Anne & $\begin{array}{l}\text { BA in elementary } \\
\text { education; MA and } \\
\text { specialist in reading }\end{array}$ & & & 21 & $\begin{array}{l}23 \\
70 \mathrm{~min} .\end{array}$ & & & 14 & $\begin{array}{l}23 \\
70 \mathrm{~min} .\end{array}$ \\
\hline Grace & $\begin{array}{l}\text { BA, MA in middle grades } \\
\text { education }\end{array}$ & 6 & $\begin{array}{l}24 \\
90 \mathrm{~min} .\end{array}$ & & & 12 & $\begin{array}{l}25 \\
90 \mathrm{~min} .\end{array}$ & & \\
\hline Kurt & $\begin{array}{l}\text { BS in middle grades } \\
\text { education }\end{array}$ & & & & & 14 & $\begin{array}{l}16 \\
70 \mathrm{~min} .\end{array}$ & 1 & $\begin{array}{l}16 \\
70 \mathrm{~min} .\end{array}$ \\
\hline May & $\begin{array}{l}\text { BA, MA in middle grades } \\
\text { education }\end{array}$ & 6 & $\begin{array}{l}52 \\
50 \mathrm{~min} .\end{array}$ & 16 & $\begin{array}{l}43 \\
50 \mathrm{~min} .\end{array}$ & & & & \\
\hline Tami & $\begin{array}{l}\text { BA in middle grades } \\
\text { education }\end{array}$ & 3 & $\begin{array}{l}33 \\
50 \mathrm{~min} .\end{array}$ & & & 6 & $\begin{array}{l}33 \\
50 \mathrm{~min} .\end{array}$ & & \\
\hline
\end{tabular}


Table 2

Percentage of Modal Types Used for Teacher Communication in Each Discipline

\begin{tabular}{|c|c|c|c|c|c|c|c|c|}
\hline \multirow[t]{2}{*}{ Teacher } & \multicolumn{2}{|l|}{ Earth Science } & \multicolumn{2}{|l|}{ Language Arts } & \multicolumn{2}{|l|}{ Mathematics } & \multicolumn{2}{|l|}{ Social Studies } \\
\hline & Mode & $\%$ & Mode & $\%$ & Mode & $\%$ & Mode & $\%$ \\
\hline \multirow[t]{4}{*}{ Alice } & & & Writing & 68 & & & Writing & 51 \\
\hline & & & Non-iconic visual & 13 & & & Image & 25 \\
\hline & & & Image & 10 & & & Gesture & 15 \\
\hline & & & Gesture & 8 & & & Non-iconic visual & 9 \\
\hline \multirow[t]{5}{*}{ Annette } & & & Writing & 66 & & & Writing & 43 \\
\hline & & & Gesture & 14 & & & Gesture & 27 \\
\hline & & & Non-iconic visual & 12 & & & Image & 26 \\
\hline & & & Image & 8 & & & Non-iconic visual & 3 \\
\hline & & & $3-\mathrm{D}$ & 1 & & & & \\
\hline \multirow[t]{5}{*}{ Grace } & Gesture & 37 & & & Non-iconic visual & 39 & & \\
\hline & Writing & 23 & & & Writing & 26 & & \\
\hline & Image & 17 & & & Gesture & 21 & & \\
\hline & $3-\mathrm{D}$ & 14 & & & Image & 9 & & \\
\hline & Non-iconic visual & 9 & & & $3-\mathrm{D}$ & 6 & & \\
\hline \multirow[t]{5}{*}{ Kurt } & & & & & Non-iconic visual & 41 & Image & 36 \\
\hline & & & & & Gesture & 26 & Writing & 31 \\
\hline & & & & & Writing & 18 & Gesture & 29 \\
\hline & & & & & Image & 13 & Non-iconic visual & 5 \\
\hline & & & & & $3-\mathrm{D}$ & 2 & & \\
\hline \multirow[t]{5}{*}{ May } & Writing & 38 & Writing & 66 & & & & \\
\hline & Gesture & 30 & Non-iconic visual & 18 & & & & \\
\hline & Image & 21 & Gesture & 9 & & & & \\
\hline & $3-\mathrm{D}$ & 9 & Image & 6 & & & & \\
\hline & Non-iconic visual & 2 & & & & & & \\
\hline \multirow[t]{5}{*}{ Tami } & Writing & 37 & & & Writing & 33 & & \\
\hline & Gesture & 20 & & & Non-iconic visual & 29 & & \\
\hline & Image & 19 & & & Gesture & 18 & & \\
\hline & $3-\mathrm{D}$ & 19 & & & Image & 15 & & \\
\hline & Non-iconic visual & 6 & & & $3-\mathrm{D}$ & 6 & & \\
\hline \multirow[t]{5}{*}{ Total } & Writing & 33 & Writing & 67 & Non-iconic visual & 36 & Writing & 42 \\
\hline & Gesture & 29 & Non-iconic visual & 14 & Writing & 26 & Image & 29 \\
\hline & Image & 19 & Gesture & 10 & Gesture & 22 & Gesture & 24 \\
\hline & $3-\mathrm{D}$ & 14 & Image & 8 & Image & 12 & Non-iconic visual & 6 \\
\hline & Non-iconic visual & 6 & & & $3-\mathrm{D}$ & 5 & & \\
\hline
\end{tabular}


Table 3.

Percentage of Gestural Types Used for Teacher Communication in Each Discipline

\begin{tabular}{|c|c|c|c|c|c|c|c|c|}
\hline \multirow{2}{*}{ Teacher } & \multicolumn{2}{|c|}{ Earth Science } & \multicolumn{2}{|c|}{ Language Arts } & \multicolumn{2}{|c|}{ Mathematics } & \multicolumn{2}{|c|}{ Social Studies } \\
\hline & Type of Gesture & $\%$ & Type of Gesture & $\%$ & Type of Gesture & $\%$ & Type of Gesture & $\%$ \\
\hline Alice & & & $\begin{array}{l}\text { Action } \\
\text { Pointing } \\
\text { Distinction } \\
\text { Metaphoric } \\
\text { Magnitude } \\
\text { Movement } \\
\text { Shape } \\
\end{array}$ & $\begin{array}{l}36 \\
27 \\
14 \\
9 \\
5 \\
5 \\
5\end{array}$ & & & $\begin{array}{l}\text { Pointing } \\
\text { Action } \\
\text { Magnitude } \\
\text { Metaphoric } \\
\text { Movement } \\
\text { Distinction }\end{array}$ & $\begin{array}{l}38 \\
27 \\
19 \\
8 \\
4 \\
4\end{array}$ \\
\hline Annette & & & $\begin{array}{l}\text { Distinction } \\
\text { Action } \\
\text { Pointing } \\
\text { Metaphoric } \\
\text { Movement } \\
\text { Shape }\end{array}$ & $\begin{array}{l}33 \\
28 \\
17 \\
11 \\
6 \\
6\end{array}$ & & & $\begin{array}{l}\text { Pointing } \\
\text { Action } \\
\text { Distinction } \\
\text { Magnitude } \\
\text { Shape } \\
\text { Metaphoric } \\
\text { Movement }\end{array}$ & $\begin{array}{l}39 \\
27 \\
12 \\
12 \\
5 \\
2 \\
2\end{array}$ \\
\hline Grace & $\begin{array}{l}\text { Movement } \\
\text { Pointing } \\
\text { Spatial Position } \\
\text { Action } \\
\text { Shape } \\
\text { Distinction } \\
\text { Magnitude } \\
\text { Metaphoric } \\
\end{array}$ & $\begin{array}{l}30 \\
20 \\
15 \\
13 \\
7 \\
5 \\
5 \\
4 \\
\end{array}$ & & & $\begin{array}{l}\text { Pointing } \\
\text { Shape } \\
\text { Metaphoric } \\
\text { Action } \\
\text { Movement: } \\
\text { Distinction } \\
\text { Spatial Position }\end{array}$ & $\begin{array}{l}60 \\
13 \\
10 \\
8 \\
4 \\
2 \\
2\end{array}$ & & \\
\hline Kurt & & & & & $\begin{array}{l}\text { Pointing } \\
\text { Shape } \\
\text { Movement } \\
\text { Distinction } \\
\text { Spatial Position } \\
\text { Magnitude } \\
\end{array}$ & $\begin{array}{l}59 \\
19 \\
11 \\
4 \\
4 \\
4\end{array}$ & $\begin{array}{l}\text { Action } \\
\text { Pointing } \\
\text { Distinction } \\
\text { Metaphoric } \\
\text { Magnitude }\end{array}$ & $\begin{array}{l}59 \\
18 \\
12 \\
6 \\
6\end{array}$ \\
\hline May & $\begin{array}{l}\text { Movement } \\
\text { Pointing } \\
\text { Shape } \\
\text { Spatial Position } \\
\text { Action } \\
\text { Magnitude } \\
\text { Distinction } \\
\text { Metaphoric }\end{array}$ & $\begin{array}{l}35 \\
21 \\
11 \\
10 \\
8 \\
8 \\
3 \\
3 \\
\end{array}$ & $\begin{array}{l}\text { Action } \\
\text { Pointing } \\
\text { Metaphoric } \\
\text { Distinction } \\
\text { Movement }\end{array}$ & $\begin{array}{l}48 \\
24 \\
19 \\
5 \\
5\end{array}$ & & & & \\
\hline Tami & $\begin{array}{l}\text { Movement } \\
\text { Pointing } \\
\text { Spatial Position } \\
\text { Action } \\
\text { Magnitude } \\
\text { Shape } \\
\text { Metaphoric }\end{array}$ & $\begin{array}{l}4 \\
22 \\
10 \\
7 \\
7 \\
5 \\
2 \\
\end{array}$ & & & $\begin{array}{l}\text { Pointing } \\
\text { Shape } \\
\text { Action } \\
\text { Metaphoric } \\
\text { Distinction } \\
\text { Spatial Position }\end{array}$ & $\begin{array}{l}58 \\
17 \\
8 \\
8 \\
6 \\
3\end{array}$ & & \\
\hline Total & $\begin{array}{l}\text { Movement } \\
\text { Pointing } \\
\text { Spatial Position } \\
\text { Action } \\
\text { Shape } \\
\text { Magnitude } \\
\text { Distinction } \\
\text { Metaphoric } \\
\end{array}$ & $\begin{array}{l}37 \\
21 \\
12 \\
9 \\
8 \\
7 \\
3 \\
3 \\
\end{array}$ & $\begin{array}{l}\text { Action } \\
\text { Pointing } \\
\text { Distinction } \\
\text { Metaphoric } \\
\text { Movement } \\
\text { Shape } \\
\text { Magnitude }\end{array}$ & $\begin{array}{l}37 \\
23 \\
17 \\
13 \\
5 \\
4 \\
2\end{array}$ & $\begin{array}{l}\text { Pointing } \\
\text { Shape } \\
\text { Metaphoric } \\
\text { Movement } \\
\text { Action } \\
\text { Distinction } \\
\text { Spatial Position } \\
\text { Magnitude } \\
\end{array}$ & $\begin{array}{l}59 \\
16 \\
6 \\
5 \\
5 \\
4 \\
3 \\
1 \\
\end{array}$ & $\begin{array}{l}\text { Action } \\
\text { Pointing } \\
\text { Magnitude } \\
\text { Distinction } \\
\text { Metaphoric } \\
\text { Movement } \\
\text { Shape }\end{array}$ & $\begin{array}{l}38 \\
32 \\
12 \\
9 \\
5 \\
2 \\
2\end{array}$ \\
\hline
\end{tabular}


